Erratum

\title{
Erratum: Abdou, A. A. N. and Khamsi, M.A. Fixed Points of Kannan Maps in the Variable Exponent Sequence Spaces $\ell_{p(\cdot)}$. Mathematics 2020, 8, 76
}

\author{
Afrah A. N. Abdou ${ }^{1,2}$ and Mohamed Amine Khamsi ${ }^{3, *}$ (i) \\ 1 Department of Mathematics, Faculty of Sciences, King Abdulaziz University, Jeddah 21589, Saudi Arabia; \\ aabdou@kau.edu.sa or aabdou@uj.edu.sa \\ 2 Department of Mathematics, Faculty of Sciences, University of Jeddah, Jeddah 23218, Saudi Arabia \\ 3 Department of Mathematical Sciences, The University of Texas at El Paso, El Paso, TX 79968, USA \\ * Correspondence: mohamed@utep.edu; Tel.: +1-915-252-1777; Fax: +1-915-747-6763
}

Received: 25 March 2020; Accepted: 25 March 2020; Published: 14 April 2020

\begin{abstract}
Kannan maps have inspired a branch of metric fixed point theory devoted to the extension of the classical Banach contraction principle. The study of these maps in modular vector spaces was attempted timidly and was not successful. In this work, we look at this problem in the variable

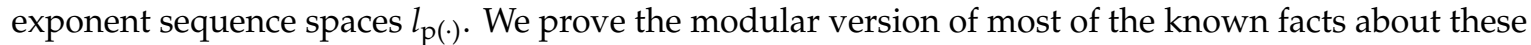
maps in metric and Banach spaces. In particular, our results for Kannan nonexpansive maps in the modular sense were never attempted before.
\end{abstract}

Keywords: electrorheological fluids; fixed point; Kannan contraction mapping; Kannan nonexpansive mapping; modular vector spaces; Nakano

The authors wish to make the following corrections to this paper [1]:

Change in Affiliation

We would like to change the authors' Afrah Abdou affiliation on Page 1 of paper [1] from:

Department of Mathematics, Faculty of Sciences, Jeddah University, Jeddah 23218, Saudi Arabia to the correct version, as follows:

Department of Mathematics, Faculty of Sciences, University of Jeddah, Jeddah 23218, Saudi Arabia The authors would like to apologize for any inconvenience caused to the readers by this change. The change does not affect the scientific results. The manuscript will be updated and the original will remain online on the article webpage.

Conflicts of Interest: The authors declare no conflict of interest.

\section{Reference}

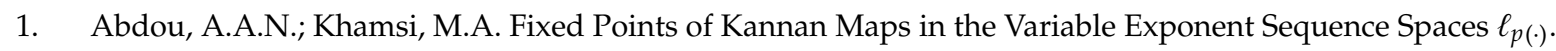
Mathematics 2020, 8, 76. [CrossRef]

(C) 2020 by the authors. Licensee MDPI, Basel, Switzerland. This article is an open access article distributed under the terms and conditions of the Creative Commons Attribution (CC BY) license (http://creativecommons.org/licenses/by/4.0/). 